\title{
An Evaluation of Antioxidant Potential of Flavonoid Eriodictyol in Isoproterenol-Induced Myocardial Infarction in Rats
}

\author{
Preethi Hariharan, Mariyappan Palani, Manju Vaiyapuri*
}

Department of Biochemistry Periyar University, Salem, Tamil Nadu, INDIA.

\begin{abstract}
Aim: The study was designed to evaluate the antioxidant potential of eriodictyol on lipid peroxidation caused due to isoproterenol induced myocardial infarction in albino male wistar rats. Methods: Myocardial Infarction was induced by subcutaneous injection of isoproterenol, $85 \mathrm{mg} / \mathrm{Kg}$ body weight after a pretreatment period of 45 days with eriodictyol in various doses $50 \mathrm{mg}, 100 \mathrm{mg}$ and $200 \mathrm{mg}$ per $\mathrm{Kg}$ body weight through intragastric intubation. The standard drug metoprolol succinate was administered orally at a dose of $2.5 \mathrm{mg}$ per $\mathrm{Kg}$ body weight for 45 days followed by ISO induced myocardial infarction. Results: The study showed significant increase in the levels of thiobarbituric acid reactive substances, lipid hydroperoxides and conjugated dienes both in plasma and heart tissue with considerable decrease in the levels of enzymatic and non-enzymatic antioxidants in ISO induced myocardial infracted rats. The oral administration of eriodictyol showed significant decrease in lipid peroxidation products and with significant increase in the levels of antioxidants. The cardio protective role of eriodictyol was further assessed by histopathological studies. Conclusion: The results indicate that the oral administration of metoprolol succinate also modulates the lipid peroxidation and the antioxidant status in the ISO induced myocardial infracted rats.
\end{abstract}

Key words: Myocardial infarction (MI), Isoproterenol (ISO), Eriodictyol (E), Lipid peroxidation, Antioxidants, Acute Myocardial Infarction (AMI).

\section{INTRODUCTION}

Cardiovascular diseases is the leading cause of death both in men and women affecting 7 million people every year worldwide. ${ }^{1}$ Myocardial infarction is the most important form of Ischemic Heart Disease (IHD), in which ischemia causes the death of heart muscles, characterized by necrotic cell death because of the breakdown of cellular energy metabolism. ${ }^{2}$ Isoproterenol is a synthetic catecholamine and $\beta 1$-adrenergic agonist that induces severe stress in the cardiac muscles leading to the development of MI. ${ }^{3}$ Myocardial necrosis induced by ISO can be accounted to adenyl cyclase activation of $\mathrm{Ca}$ and $\mathrm{Na}$ channels causing an exaggerated calcium inflow, coupled to excess contraction of the cardiac muscles leading to energy consumption and cellular death. ${ }^{4}$ Oxygen radicals have been associated with a variety of pathological process such as ischemic injury to the heart, respiratory distress syndrome in adults, atherosclerosis, aging, ethanol induced liver injury and cancer. ${ }^{5}$ Oxidation of the catecholamines can increase the rate of production of free radicals. Oxidative corrosion of membrane polyunsaturated fatty acids by these free radicals within the myocardium is associated with increased levels of thiobarbituric acid reactive substances (TBARS), lipid radicals (L); lipid peroxy radical (LOO) and lipid hydroperoxides $(\mathrm{LOOH})$ as observed during the initial stages of MI influenced by oxidative stress. ${ }^{6}$

Eriodictyol is 2-(3,4-Dihydroxyphenyl)5,7-dihydroxy-2,3-dihydro-4H-chromen-
Submission Date: 08-03-2017;

Revision Date: 18-03-2017;

Accepted Date: 10-04-2017

DOI: 10.5530/ijper.51.4.90

Correspondence: Manju Vaiyapuri, Assistant Professor, Department of Biochemistry Periyar University, Salem, Tamil Nadu, INDIA. Tel: +91 9940247576; E-mail: manjucb11@gmail. com

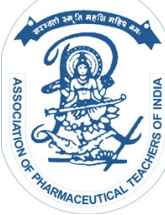

www.ijper.org 
4-one (Figure 1) is a flavanone extracted from Yerba Santa (Eriodictyoncalifornicum) ${ }^{7}$ and thetwigsof Millettia duchesnei. ${ }^{8}$ Eriodictyol present in lemon fruit, is found to suppress oxidative stress in serum, liver, and kidney of diabetic rats in combination with hesperidin. ${ }^{9}$ Experiments shows that eriodictyol has antioxidant properties $^{10,11}$ anti-parasitic ${ }^{12}$ and even anticancer properties.$^{13}$

Metoprolol succinate (Figure 2) is a $\beta 1$ selective adrenoceptor blocking agent are hemodynamically and energetically beneficial in the treatment of myocardial failure. ${ }^{14}$ Metoprolol also reduces the forces of contraction of heart muscle and thereby lowers the blood pressure, by reducing the heart rate and the force of muscle contraction, reduces the need for oxygen by heart ${ }^{15}$ and is recommended for treatment of myocardial infarction. In the present study an attempt has been made to elucidate the antioxidant property of eriodictyol in comparison with metoprolol succinate as standard.

\section{MATERIALS AND METHODS}

\section{Drugs and chemicals}

Eriodictyol, Isoproterenol hydrochloride, polyethylene glycol, nitrobluetetrazolium, glutathione, and nicotinamide adenine dinucleotide were purchased from Sigma Aldrich chemical company, St.louis, USA. All other chemicals used in the study were of analytical grade.

\section{Formulation and administration of the drug}

Eriodictyol dissolved in 5\% Tween $80,20 \%$ polyethylene glycol and $75 \%$ saline was orally administered to the animals ${ }^{16}$ by intragastric intubation. Each animal belonging to different groups were administered with $1.0 \mathrm{ml}$ of the drug suspension at a dose of $50 \mathrm{mg}$ per $\mathrm{kg}$ body weight for group 4 and 7, $100 \mathrm{mg}$ per kg body weight for group 5 and 8, $200 \mathrm{mg}$ per $\mathrm{kg}$ body weight for group 6 and 9 for 45 days. The standard drug metoprolol succinate is dissolved in distilled water and administered in a single dose of $2.5 \mathrm{mg}^{17}$ per $\mathrm{Kg}$ body weight for group 3 and 10 for 45 days.

\section{Experimental animals}

Male Albino Wistar rats weighing 130-160 g were purchased from Sri Venkateswara Enterprises, Bangalore, India. Animals were housed in polypropylene cages with 6 rats per cage. Animals were fed on standard pellets and water was provided ad libitum. Cages were maintained under standard condition of temperature, $25 \pm 2^{\circ} \mathrm{C}$. The study was approved by the Animal Ethical Committee of Periyar University, Salem, Tamilnadu. (1085/ac/07/ PUIAEC/OCT-2012/02).

\section{Experimental Design}

Experimental Design: The experimental rats were randomly divided into ten groups consisting of 6 rats each. Group 1 (control). Animals received standard diet and drinking water ad libitum and served as control group. Group 2 (ISO). Animals received standard laboratory diet and drinking water ad libitum for 45 days and was treated with ISO in two doses $(85 \mathrm{mg} / \mathrm{kg} \text { body weight })^{18}$ by subcutaneous injection on 46 and $47^{\text {th }}$ day at an interval of 24 hs.

Group 3 (Metoprolol Succinate positive)- Animals received metoprolol succinate via intragastric intubation at a daily dosage of $2.5 \mathrm{mg} / \mathrm{Kg}$ body weight for a period of 45 days.

Group 4 (Eriodictyol 50 positive) - Animals received eriodictyol via intragastric intubation at a daily dosage of $50 \mathrm{mg} / \mathrm{Kg}$ body weight for a period of 45 days.

Group 5 (Eriodictyol 100 positive) - Animals received eriodictyol via intragastric intubation at a daily dosage of $100 \mathrm{mg} / \mathrm{Kg}$ body weight for a period of 45 days.

Group 6 (Eriodictyol 200 positive). Animals received eriodictyol via intragastric intubation at a daily dosage of $200 \mathrm{mg} / \mathrm{Kg}$ body weight for a period of 45 days.

Group 7 (Eriodictyol 50 AMI). Animals received eriodictyol via intragastric intubation at a daily dosage of $50 \mathrm{mg} / \mathrm{Kg}$ body weight for a period of 45 days. Animals where was treated with ISO in two doses $(85 \mathrm{mg} / \mathrm{kg}$ body weight) by subcutaneous injection on 46 and $47^{\text {th }}$ day at an interval of $24 \mathrm{hs}$ to induce AMI

Group 8 (Eriodictyol 100 AMI). Animals received eriodictyol via intragastric intubation at a daily dosage of $100 \mathrm{mg} / \mathrm{Kg}$ body weight for a period of 45 days. Animals where was treated with ISO in two doses $(85 \mathrm{mg} /$ $\mathrm{kg}$ body weight) by subcutaneous injection on 46 and 47 th day at an interval of $24 \mathrm{hs}$ to induce AMI

Group 9 (Eriodictyol 200 AMI). Animals received eriodictyol via intragastric intubation at a daily dosage of $200 \mathrm{mg} / \mathrm{Kg}$ body weight for a period of 45 days. Animals where was treated with ISO in two doses $(85 \mathrm{mg} /$ $\mathrm{kg}$ body weight) by subcutaneous injection on 46 and $47^{\text {th }}$ day at an interval of 24 hs to induce AMI

Group 10 (Metoprolol Succinate AMI). Animals received metoprolol succinate via intragastric intubation at a daily dosage of $2.5 \mathrm{mg} / \mathrm{Kg}$ body weight for a period of 45 days. Animals were treated with ISO in two doses ( $85 \mathrm{mg} / \mathrm{kg}$ body weight) by subcutaneous injection on 46 and $47^{\text {th }}$ day at an interval of 24 hs to induce AMI

The animals were anaesthetized and were sacrificed by cervical dislocation. Blood was withdrawn by retro orbital puncture in an anticoagulant coated tube and the 
plasma separated after centrifugation was used for biochemical investigation. Heart was dissected out, cleared of blood were transferred in ice cold saline. Heart tissue was homogenized in a suitable buffer, centrifuged and used for various biochemical analysis.

\section{Preparation of hemolysate}

Blood was collected in heparinized tubes, plasma separated by centrifuged at 3000x g for 5 minutes was collected and used for the biochemical estimations.

\section{Preparation of tissue homogenate}

The excised heart tissue was removed and was immediately washed with ice cold saline. The tissue was homogenized in an appropriate buffer using a tissue homogenizer.

\section{Biochemical Estimations}

Lipid peroxidation was measured by estimating the level of thiobarbituric acid reactive substances in tissues by the method of Ohkawa (1976) ${ }^{19}$ and the plasma levels were estimated by the method of Yagi (1976). ${ }^{20}$ Lipid Hydro peroxides was measured by the method of Jiang $(1992)^{21}$ and conjugated dienes by the method of Rao (1968). ${ }^{22}$ Antioxidant enzymes SOD and Catalase was estimated by Kakkar (1984) ${ }^{23}$ and Sinha $(1972)^{24}$ respectively. Glutathione peroxidases, Reduced Glutathione, and Glutathione -s-transferase by Rotruck (1973), ${ }^{25}$ Boyne \& Ellman (1972) ${ }^{26}$ and Habig (1977). ${ }^{27}$ Non Enzymatic antioxidants (Vitamin C and Vitamin E) in the plasma and heart tissue was estimated by Omaye et al. $(1979)^{28}$ and Baker et al. $(1951)^{29}$

\section{Histopathological Studies}

The rats were sacrificed at the end of the experimental period, the dissected heart were washed in ice cold saline. The heart tissues were fixed in 10\% buffered neutral formalin solution. After fixation the heart tissue was processesed by embedding in paraffin. Serial sections of the tissues were cut and each section was stained with

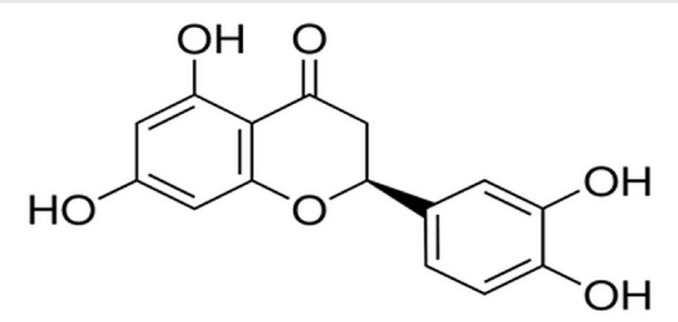

Figure 1: Structure of Eriodictyol, its molecular formula is: C15H1206. Molecular weight is $288.5 \mathrm{~g} / \mathrm{mol}$.. hematoxylin and eosin. The slides were observed under a light microscope and photomicrographs were taken.

\section{Statistical Analysis}

The results are tabulated and graphically represented as the mean \pm SD. Statistical analysis was performed using one way analysis of variance. All data were analyzed by Duncan's multiple range test for group mean comparison using statistical program SPSS 16.00 for windows. Values not sharing a common superscript (a-h) differ significantly with each other. The findings were considered statistically significant if $\mathrm{p}$ value $<0.05 .^{30}$

\section{RESULTS}

\section{Histopathological Observations}

Figure 3 shows the cardiac architecture for various experimental groups. Histopathological analysis of the control (group 1), metoprolol succinate alone (group 3) and eriodictyol alone treated groups (group 4, 5, 6) showed normal cardiac fibers. It is observed that in ISO induced (group 2), myocardial infracted heart sessions showed severe cardiac damage with inflammatory cell infiltration. The pretreatment with eriodictyol showed concentration dependent decrease in the degree of the<smiles>COCCc1ccc(OCC(O)CNC(C)C)cc1</smiles>

Figure 2: Structure of Metoprolol succinate, its molecular formula is: C34H56N2O10. Molecular weight is $652.8 \mathrm{~g} / \mathrm{mol}$.

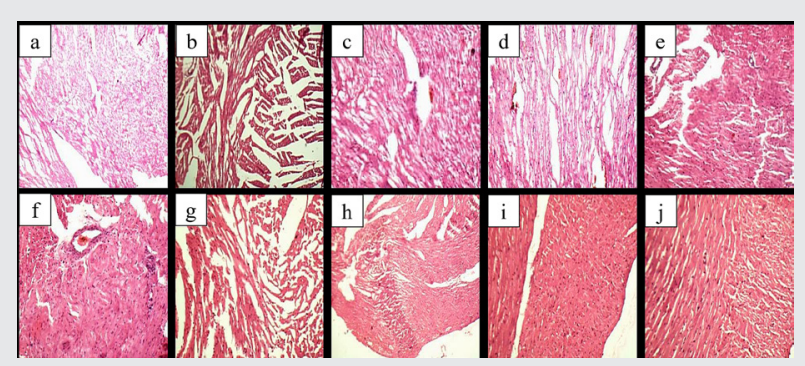

Figure 3: Histopathology changes in the myocardial infarction of control and experimental rats. a) Group I Normal appearance of the myocardial tissue in the control rats. b) Group II shows severe cardiac necrosis with the splitting of cardiac myocytes. c) Group III treated with metoprolol succinate alone and d), e) \& f) Group IV ,V and VI treated with various doses of eriodictyol $(50,100,200 \mathrm{~kg}$ per body weight)shows no changes in cardiac architecture. g) GroupVII shows necrosis and seperation of the muscle fibers. h) Group VIII shows very mild degree of necrosis. i) Group IX and j) Group X shows cardiac muscle cell with very less degree of infiltration of inflammatory cells and no necrosis.( 200X). 
infarct as seen in group 7,8 and 9. Metoprolol succinate pretreatment also decreased the severity of the infarct when induced with ISO as compared to the ISO alone induced group.

\section{Effect of eriodictyol and metoprolol succinate on lipid peroxidation in myocardial infarction rats}

Figure 4 and Figure 5 shows the effect of eriodictyol and metoprolol succinate on plasma and tissue levels of lipid peroxidation in the control and the experimental animals. Rats induced with ISO alone (group $2)$ showed significant increase $(p<0.05)$ in the level of TBARS, lipid hydroperoxides and conjugated dienes in the plasma and tissue compared to the normal control rats (group 1). Oral supplementation of eriodictyol (50 $\mathrm{mg}, 100 \mathrm{mg}$ and $200 \mathrm{mg} / \mathrm{kg}$ body weight) daily for a period of 45 days has helped in reversing the effect of lipid peroxides. The levels of TBARS, lipid hydro peroxides and conjugated dienes considerably reduced in the plasma and heart in group 9 and group 10 rats as compared with the ISO alone treated group. Pretreatment with eriodictyol and metoprolol succinate (group 10) significantly restored the plasma and tissue levels of TBARS, lipid hydro peroxides and conjugated dienes to near normal levels comparable to those of control rats.
Effect of eriodictyol and metoprolol succinate on plasma and tissue enzymatic antioxidants in myocardial infarction rats:

Figure 6 and Figure 7 represents the effect of eriodictyol and metoprolol succinate on SOD, catalase and glutathione peroxidase in the plasma and tissue of the normal and the ISO induced rats. ISO alone induced rats (group 2) showed significant decrease in the activities of enzymatic antioxidants in the plasma as compared to the control rats (group 1). Pretreatment with eriodictyol (group 7-9) considerably increased the levels of antioxidant enzymes compared to the ISO induced group. The levels of antioxidants enzymes also showed significant increase in animals pretreated with the standard drug, metoprolol succinate (group 10). Collating the concentration of antioxidant enzymes in group 9 and group 10, it is evident that eriodictyol is more effective in increasing the amount of both circulatory and tissue antioxidant enzymes compared to metoprolol succinate.

Effect of eriodictyol and metoprolol succinate on plasma and tissue non enzymatic antioxidants in myocardial infarction rats:

Figure 8 and Figure 9 depicts the effect of eriodictyol and metoprolol succinate on non enzymic antioxidants such as reduced glutathione, ascorbic acid and tocoph-

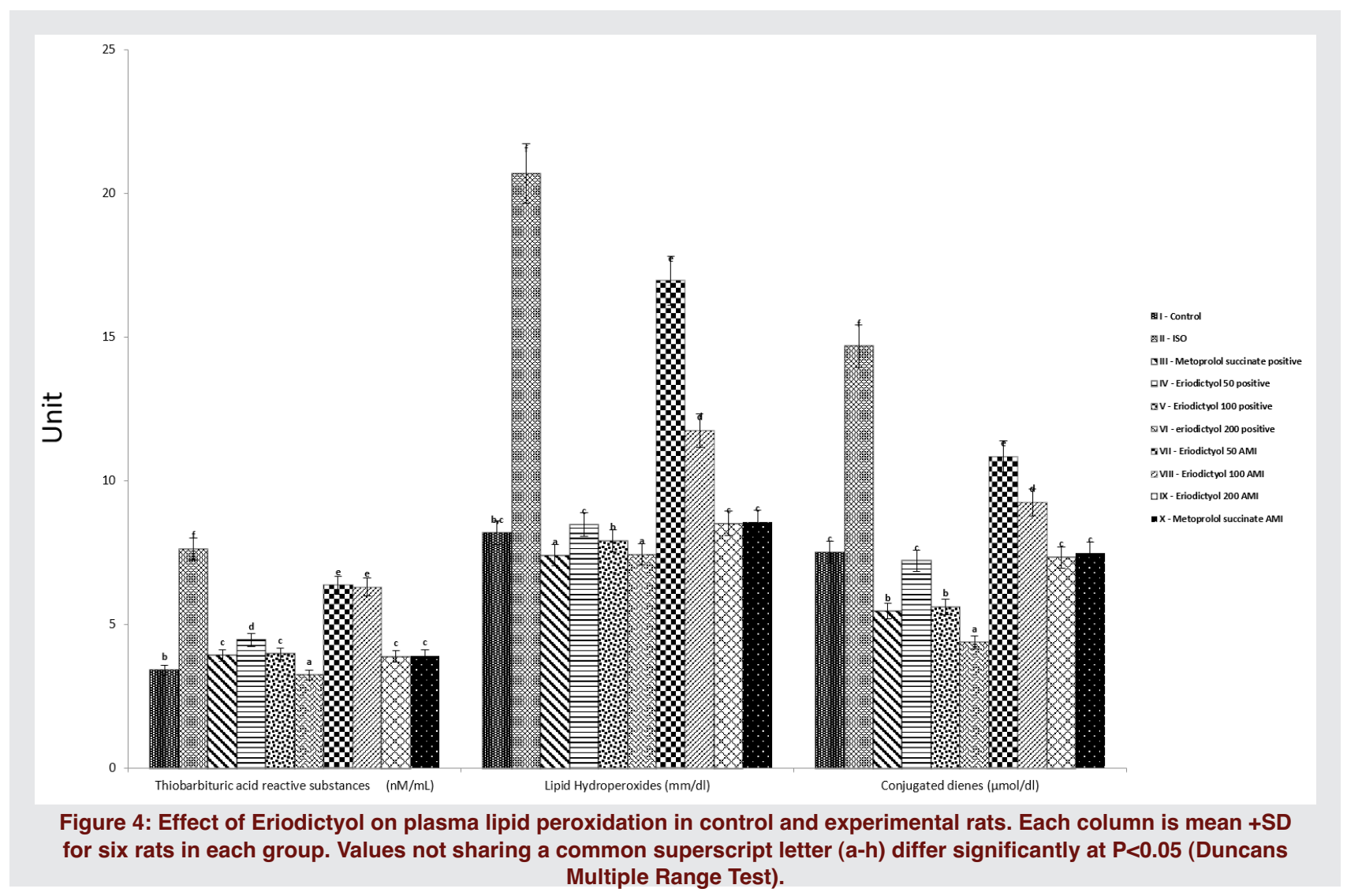




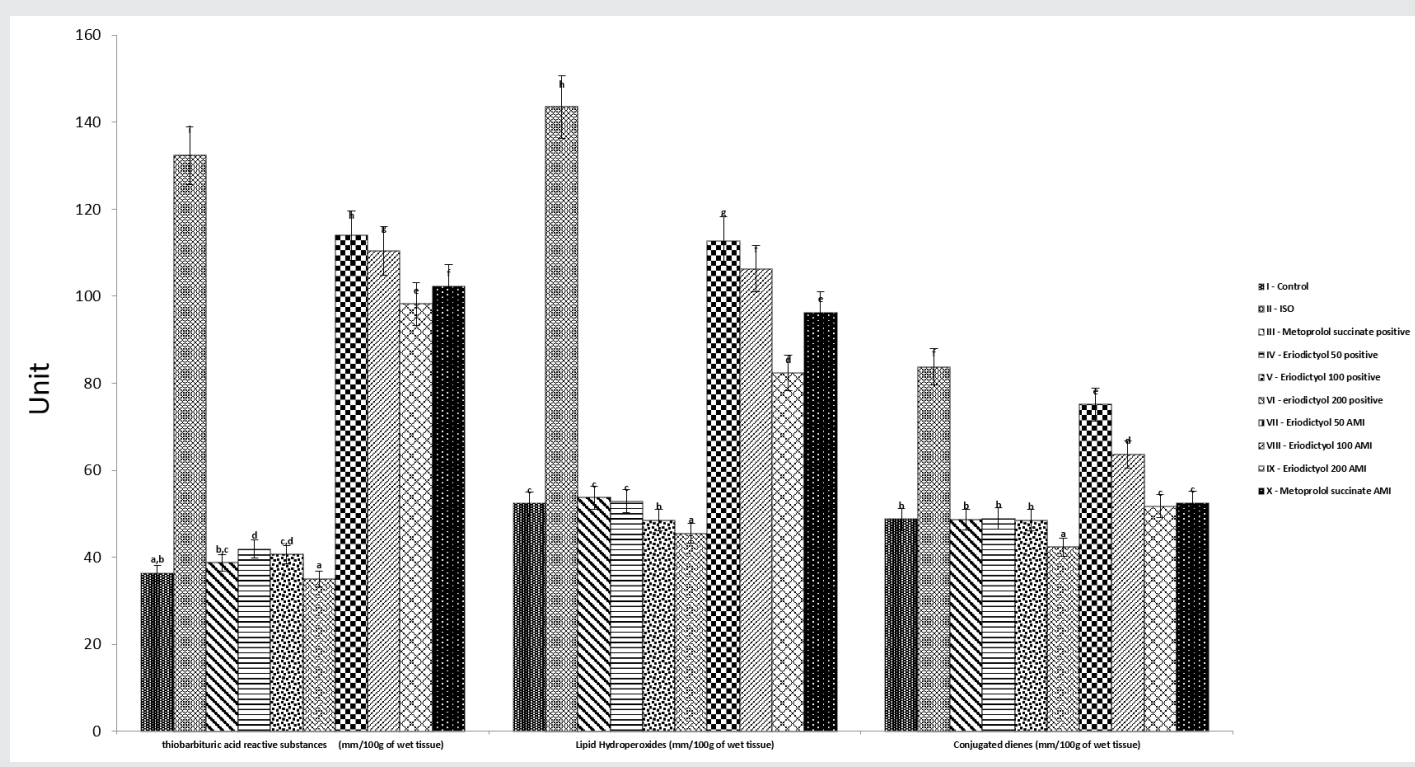

Figure 5: Effect of eriodictyol on tissue lipid peroxidation in control and experimental rats. Each column is mean +SD for six rats in each group. Values not sharing a common superscript letter (a- i) differ significantly at $\mathrm{P}<0.05$ (Duncans Multiple Range Test).

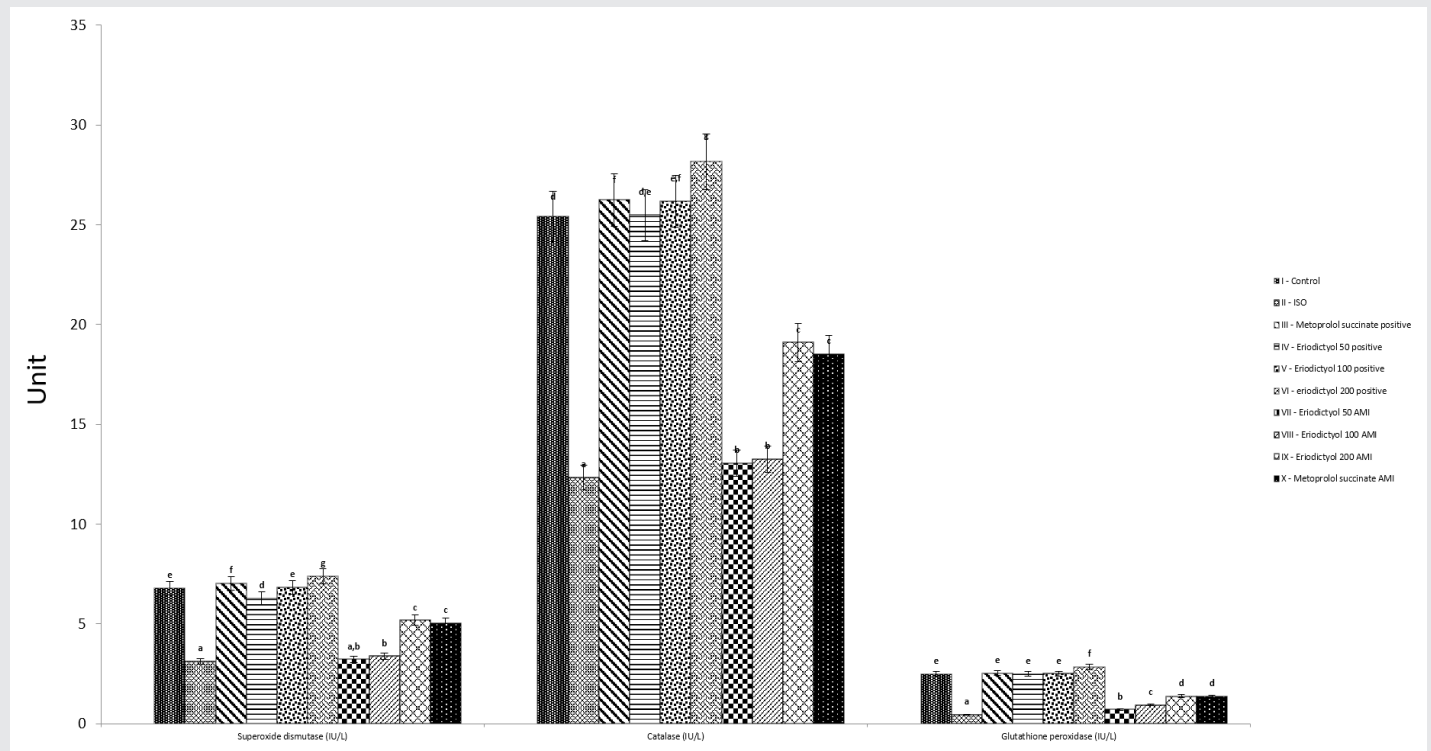

Figure 6: Effect of Eriodictyol on plasma antioxidants in control and experimental rats. Each column are mean +SD for six rats in each group. Values not sharing a common superscript letter (a-g) differ significantly at $P<0.05$ (Duncans Multiple Range Test).

erol in the plasma and tissue of normal and ISO induced rats. The ISO induced rats exhibited significant decrease in the levels of vitamin $\mathrm{C}$, vitamin $\mathrm{E}$ and reduced glutathione compared with the normal control rats. Pretreatment with eriodictyol significantly increased the plasma and tissue levels of non enzymic antioxidants in group 7- group 9 compared to the ISO alone induced group Similar results were obtained when pretreated with the metoprolol succinate. The value of plasma and tissue non enzymatic antioxidants in group 9 and group 10 shows that eriodictyol was more functional in boosting the non enzymatic antioxidants compared to metoprolol succinate.

\section{DISCUSSION}

Lipid peroxidation is a progression of deterioration of the cell membranes ${ }^{31}$ due to the increased rates of free radical production on oxidative stress ${ }^{32}$. Cell injury induced by free radical particularly reactive oxygen species is an important mechanism of cell damage in 


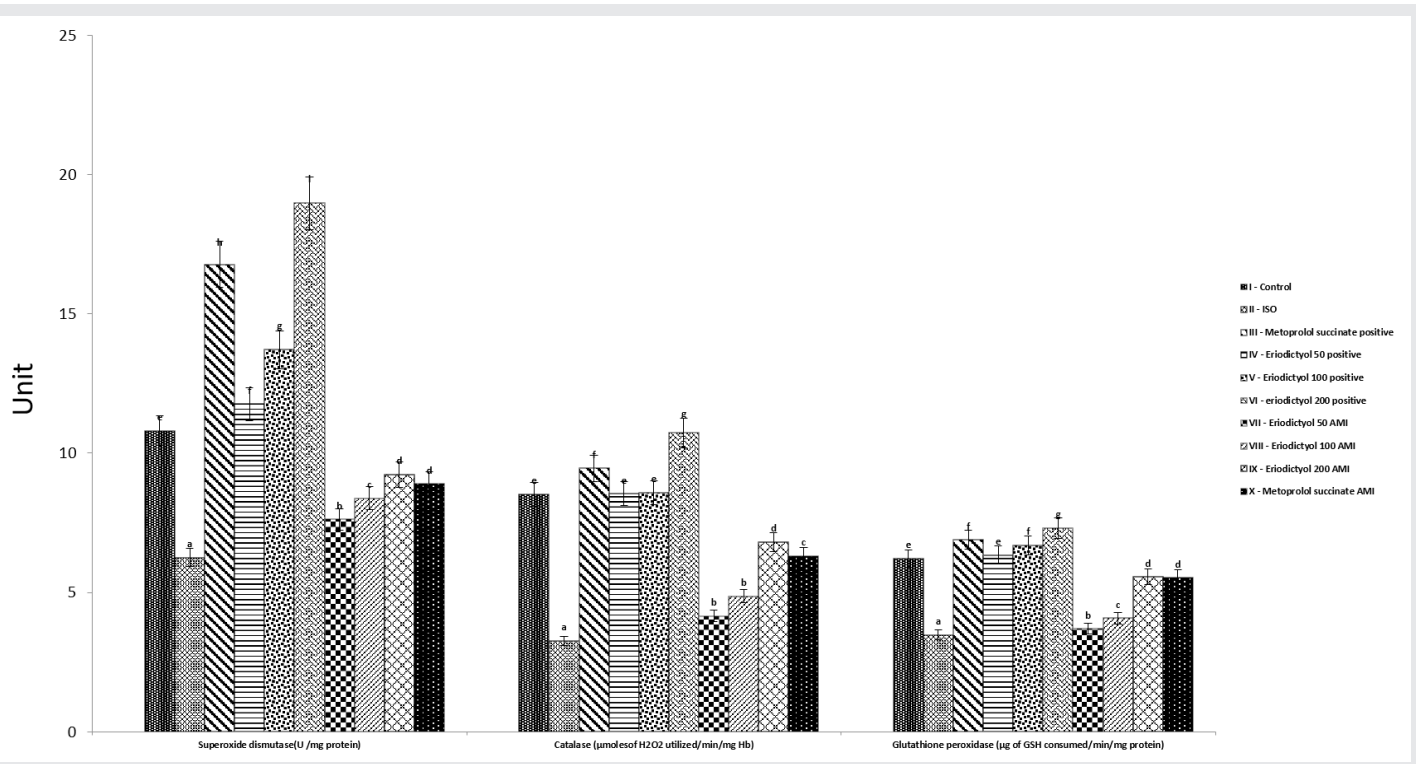

Figure 7: Effect of Eriodictyol on tissue antioxidants in control and experimental rats. Each column is mean +SD for six rats in each group. Values not sharing a common superscript letter (a- i) differ significantly at $\mathrm{P}<0.05$ (Duncans Multiple Range Test).

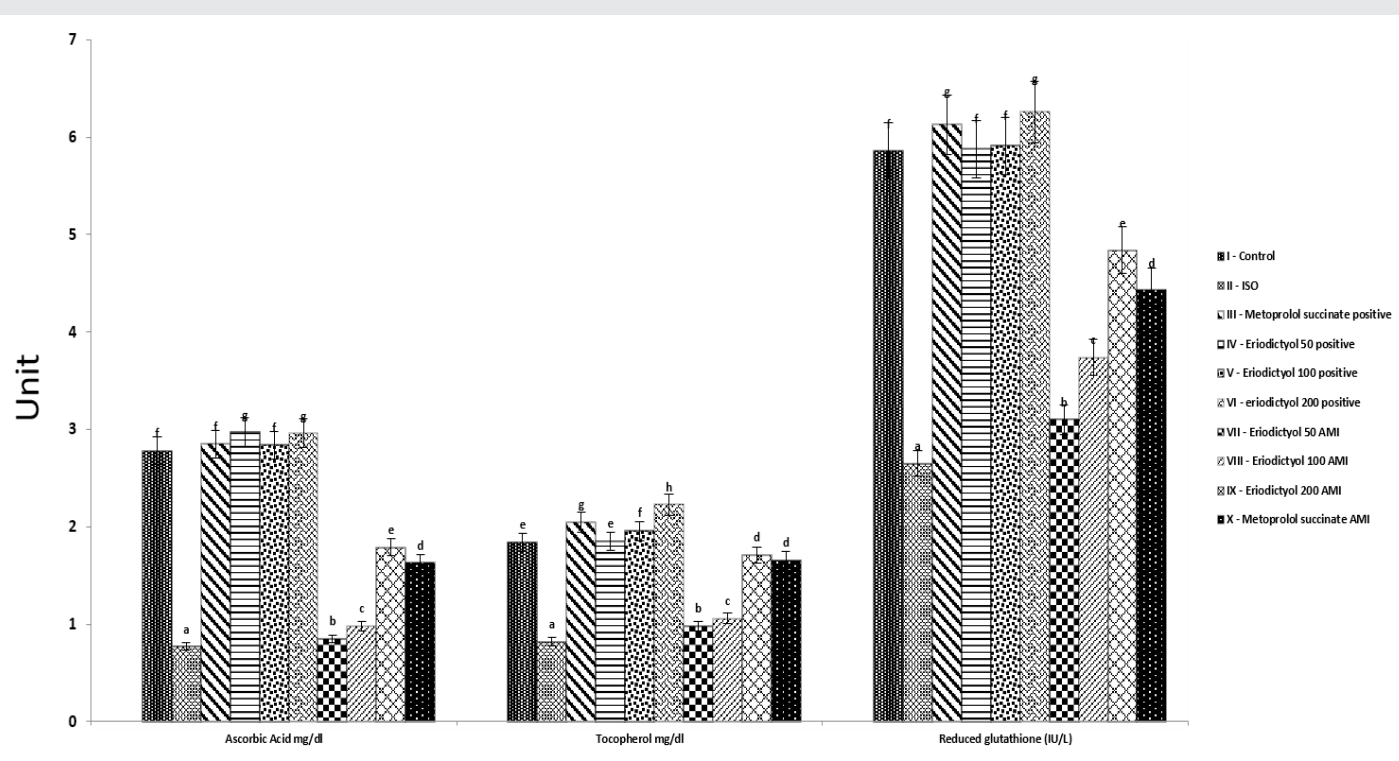

Figure 8: Effect of Eriodictyol on plasma non enzymatic antioxidants in control and experimental rats. Each column is mean +SD for six rats in each group. Values not sharing a common superscript letter (ah) differ significantly at $\mathrm{P}<0.05$ (Duncans Multiple Range Test).

pathologic conditions, ischemia and in cellular ageing. ${ }^{33}$ Catecholamines are also known to cause increased reactive oxygen species generation through oxidation and subsequent oxidative stress $^{34}$ which leads to myocardial necrosis. ${ }^{35,36}$ The formation of free radicals and the accumulation of lipid peroxides is one of the most major biochemical changes associated with myocardial damage induced by catecholamines. ${ }^{37}$ Isoproterenol is widely used model to produce infarct like lesion of myocardium in rats. ${ }^{38}$
In the present study, increased levels of lipid peroxidation (TBARS), lipid hydroperoxides and conjugated dienes in heart and plasma of ISO induced rats were observed compared to the control rats. The cells when exposed to inherently damaging agents, results in irreversible cell injury characterized by the depletion of energy stores in the form of ATP, cellular swelling caused by changes in ion concentration and water influx..$^{39,40}$ Decrease in cellular ATP, slows down the activity of cellular enzymes bringing in irreversible damage to intracellular organelles and production of ROS increases. 


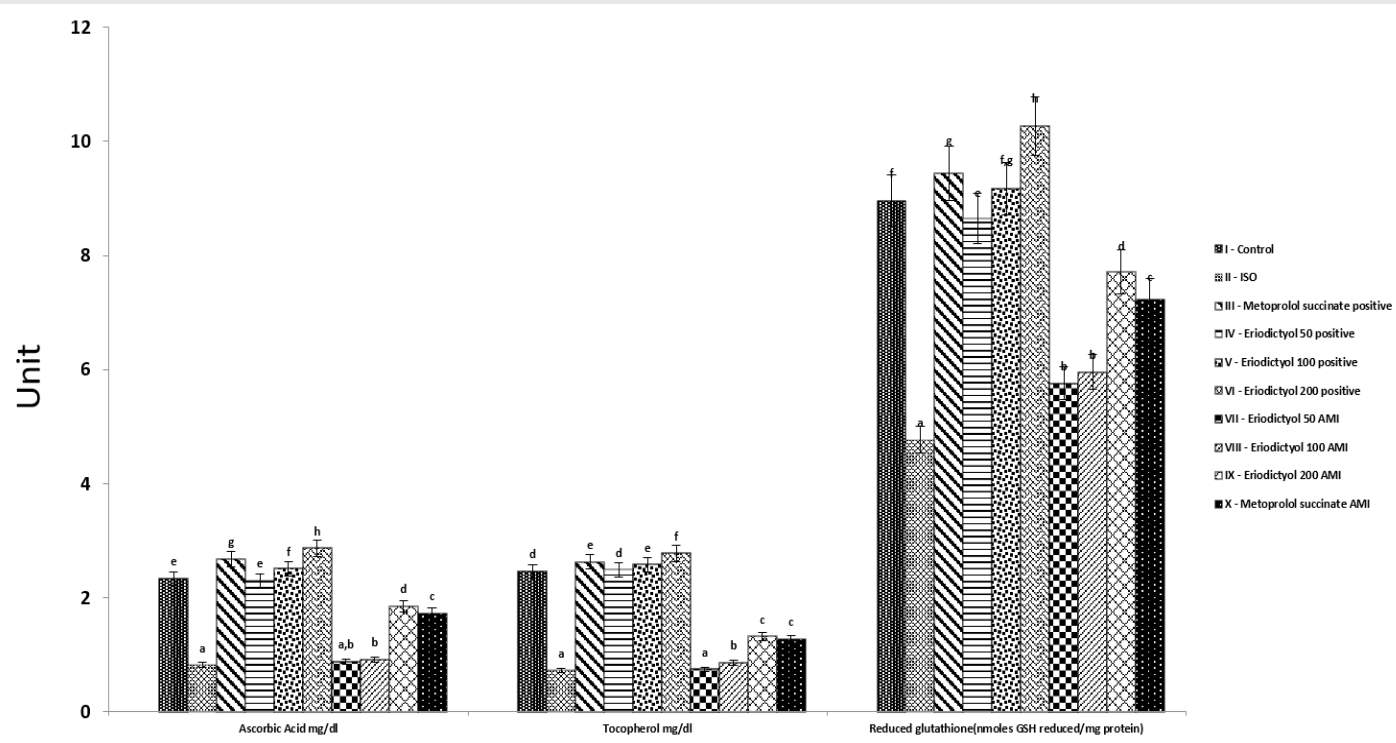

Figure 9: Effect of Eriodictyol on tissue non-enzymatic antioxidants in control and experimental rats. Each column is mean \pm SD for six rats in each group. Values not sharing a common superscript letter (a-h) differ significantly at $\mathrm{P}<0.05$ (Duncans Multiple Range Test).

The decreased levels of lipid peroxidation products (TBARS, LOOH, CD) were observed in rats pretreated with eriodictyol compared with the ISO alone induced rats. The deleterious effects of the free radicals are kept under control by a delicate balance between the rate of production and the rate of elimination of the free radicals by the defense mechanism. Antioxidants are the natural defense mechanism existing in our body, which are capable of scavenging free radicals. ${ }^{41}$ The decreased levels of lipid peroxidation products can be attributed to the increased activity of antioxidant enzymes or compounds that deactivates these free radicals. Various in vitro studies have demonstrated that flavanol, flavones and anthocyanin have considerable radical scavenging properties. ${ }^{42,43}$ This activity is attributed to their hydrogen donating ability. The phenolic groups of flavonoids serve as a source of readily available 'H'atoms such that the subsequent radicals produced can be delocalized over the flavonoid structure. ${ }^{44}$ Earlier studies on flavonoids have undoubtedly established the role of flavonoids in inhibiting lipid peroxidation in vitro and in vivo at an early stages by acting as scavengers of superoxide anion and hydroxyl radicals by terminating the propagation of free radical chain reactions. ${ }^{45,46}$ Studies have showed that eriodictyol has free radical scavenging potential ${ }^{47}$ contributing to defense against lipid peroxidation.

When the production of ROS increases or the scavenging system are ineffective, it results in an excess of these free radicals leading to a condition called oxida- tive stress. Antioxidants are molecules which can reduce the oxidative stress, by scavenging the ROS/RNS generated by various metabolic processes. ROS and RNS derived from oxygen and nitrogen are converted into free radicals which are highly unstable and are capable of damaging biologically relevant molecules such as protein, lipid and DNA can trigger a number of human diseases ${ }^{48}$ The most important antioxidant enzymes are superoxide dismutase, catalase and glutathione peroxidase. Superoxide dismutase can act on superoxide anion converting it into hydrogen peroxide. ${ }^{49}$ The hydrogen peroxide thus generated is detoxified by the catalase by converting it into $\mathrm{O}_{2}$ and $\mathrm{H}_{2} \mathrm{O} .{ }^{5 \mathrm{O}}$ Another important enzyme which has potential to remove $\mathrm{H}_{2} \mathrm{O}_{2}$ from the system is glutathione peroxidase. ${ }^{51}$ Glutathione peroxidase removes $\mathrm{H}_{2} \mathrm{O}_{2}$ by using it to oxidize reduced glutathione to oxidized glutathione. Glutathione peroxidases can also catalyze the reduction of unstable hydro peroxides at the expense of GSH. ${ }^{52}$ Hence the level of reduced glutathione available in the system can moderates the activity of antioxidant enzymes.

In the present study, ISO induced myocardial damage was evident from the decreased level of antioxidant enzymes SOD, catalase and glutathione peroxidase in ISO alone treated group. The result obtained where in agreement with similar finding in various studies concluding that catecholamine administration can lead to the depletion of energy levels in the cardiac muscle cells, leading to complex structural and biochemical changes that results in cell damage and necrosis. ${ }^{53}$ Pretreatment 
with eriodictyol has resulted in an increase in the levels of antioxidant enzymes which can be attributed to the free radical scavenging potential of eriodictyol thereby protecting the antioxidant system. Vitamin $\mathrm{C}$ and Vitamin $\mathrm{E}$ are the major non enzymatic antioxidants in aqueous and lipophilic phase respectively. Both vitamin $\mathrm{C}$ and $\mathrm{E}$ are capable of protecting the cells from oxidative cell damage. ${ }^{54}$ In our study, decreased levels of vitamin $\mathrm{C}$ and $\mathrm{E}$ which were observed in ISO induced rats were reversed on pretreatment with eriodictyol.

The Histopathological result obtained supports the finding of the study. The damage to the heart tissue in the ISO treated group can be seen as confluent necrosis of the muscle fibers with inflammatory cell infiltration and edema. Eriodictyol pretreated myocardium $(50 \mathrm{mg}$, $100 \mathrm{mg}$ )showed decrease degree of infarct as compared to the ISO treated group, whereas the myocardium pretreated with $200 \mathrm{mg} / \mathrm{kg}$ body weight showed near normal cardiac architecture. Restoration of normal heart architecture and protection of the myocardium when administered with eriodictyol in ISO induced rats reveal the protective effect of eriodictyol.

\section{CONCLUSION}

Findings from our results showed that eriodictyol protected myocardium from ISO induced myocardial infarction and structural injury via improved histopathology and biochemical parameters. In the present study, eriodictyol pretreatment prevented the ISO induced increase in lipid peroxidative parameters, showing maximum antioxidant potential at $200 \mathrm{mg} / \mathrm{kg}$ body weight. The values obtained for eriodictyol was such more significant compared to metoprolol succinate which is a standard drug generally used in the treatment of angina pectoris and cardiac failure. Hence due to its antioxidant property eriodictyol will provide an accessible medicine for heart in future. The precise molecular mechanism of eriodictyol against ISO induced myocardial infarction is underway.

\section{ACKNOWLEDGEMENT}

I take this opportunity to thank my family members, research supervisor, colleagues and friends for the continuous support, guidance and motivation to complete this research work.

\section{CONFLICT OF INTEREST}

Authors declare no conflict of interest.

\section{ABBREVIATION USED}

IHD: Ischemic Heart Disease; MI: Myocardial Infarction; ISO: Isoproterenol; TBARS: Thiobarbituric Acid Reactive Substances; LOOH: Lipid Hydroperoxides; SOD: Superoxide Dismutase; CD: Conjugated Dienes; ROS: Reactive Oxygen Species; RNS: Reactive Nitrogen Species; GSH: Reduced Glutathione.

\section{REFERENCES}

1. Thom $\mathrm{T}$, Hasse $\mathrm{N}$, et al. Heart Disease and stroke statistics - 2006 update. Circulation. 2006;113(6):85-151. https://doi.org/10.1161/ CIRCULATIONAHA.105.171600 ; PMid:16407573.

2. Saraste, Pulkki, Kallajoki, Heikkila, Laine, Mattila, et al. Cardiomyocyte apoptosis and progression of heart failure to transplantation. Eur $\mathrm{J}$ of Clinical Investigation. 1999;29(5):380-6. https://doi.org/10.1046/j.13652362.1999.00481.x.

3. Brouria FL, Findjia O, Mediania, Mougenota $\mathrm{N}$, Hanounb $\mathrm{N}$, et al. Toxic cardiac effects of catecholamine: Role of $\alpha$ adrenoceptor down regulation. Eur J Pharmacol. 2002;456:69-75. https://doi.org/10.1016/S00142999(02)02643-2.

4. Milei J, Nunez RG, Rapaport M. Pathogenesis of isoproterenol induced lesions in rat myocardium. Arch Institute Cardiol Mex. 1976;46(4):347-55. PMid:988794.

5. Gupta RK, Patel AK, Shah N, Chaudhary AK, Jha UK, Yadav UC, et al. Asian Pac J Cancer Prev. 2014;15(11):4405-9. https://doi.org/10.7314/ APJCP.2014.15.11.4405; PMid:24969860.

6. Radhiga T, Rajamanickam C, Senthil C, Pugalendi K. Effect of ursolic acid on cardiac marker enzymes, lipid profile and macroscopic enzyme mapping assay in isoproterenol induced myocardial ischemic rats. Food and Chem Toxi. 2012;50(11):3971-77. https://doi.org/10.1016/j.fct.2012.07.067 ; PMid:22898613.

7. Reichelt KV, Hartmann B, Weber B, Ley JP, Krammer GE, Engel KH. Identification of bisprenylatedbenzoic acid derivatives from Yerba santa (Eriodictyon ssp.) using sensory guided fractionation. J Agric Food Chem. 2010;58(3):1850-9. https://doi.org/10.1021/jf903286s ; PMid:20058867.

8. Ngandeu $\mathrm{F}$, et al. Rotenoid derivatives and other constituents of the twigs of Millettiaduchesnei. Photochemistry. 2008;69(1):258-63. https://doi. org/10.1016/j.phytochem.2007.05.038; PMid:17640692.

9. Miyake Y, Yamamoto K, Tsujihara N, Osawa T. Protective effects of lemon flavonoids on oxidative stress in diabetic Rats Lipids. 1998;33(7):689-95.

10. Huguet $\mathrm{Al}$, Manez S, Alcaraz MJ. Superoxide scavenging properties of flavonoids in a non-enzymic system. Z Naturforsch C. 1990;45(2):19-24. PMid:2158783.

11. Tsimogiannis DI, Oreopoulou V. Free radical scavenging and antioxidant activity of 5, 7, 3', 4'-hydroxy substituted flavonoids. Inn Food Sci Emerg Tech. 2004;5(4):523-8. https://doi.org/10.1016/j.ifset.2004.05.006.

12. Aviado DM, Bacalzo LV, Belej MA. Prevention of acute pulmonary insufficiency by eriodictyol. J Pharmacol Exp Ther. 1974;189(1):157-66. PMid:4207243.

13. Way TD, Kao MC, Lin JK. Degradation of HER2/neu by apigenin induces apoptosis through cytochrome c release and caspase-3 activation in HER2/ neu overexpressing breast cancer cells. FEBS Lett. 2005;579(1):145-52. https://doi.org/10.1016/j.febslet.2004.11.061; PMid:15620704.

14. Eichhorn EJ, Facc MD, Heesch CM, James MDH, et al. Effect of metaprolol on myocardial function and energetic in patients with non ischemic dilated cardio myopathy. JACC. 1994;24(5):1310-20. https://doi.org/10.1016/07351097(94)90114-7.

15. De vereaux PJ, Yang H, Yusuf S, Guyatt G, Leslie K, Villar JC, et al. Effects of extended release metaprolol succinate in patients undergoing non cardiac surgery: a randomized controlled trial. Lancet. 2008;371(9627):1839-47. https://doi.org/10.1016/S0140-6736(08)60601-7.

16. Rossato MF, Trevisan G, Walker CIB, ZeniKlafke J, de Oliveira AP, Villarinho JG, Eriodictyol: A flavonoid antagonist of the TRPV1 receptor with antioxidant activity Biochemical Pharmacology. 2011;81(4):544-51. https:// doi.org/10.1016/j.bcp.2010.11.004; PMid:21087598. 
17. Nandi U, Karmakar S, Das AK, Ghosh B, Padman A, Chatterjee N, Pal TK. Pharmacokinetics, pharmacodynamics and toxicity of a combination of metoprolol succinate and telmisartan in Wistar albino rats: Safety profiling. Regulatory Toxicology and Pharmacology. 2013;65(1):68-78. https://doi. org/10.1016/j.yrtph.2012.11.001; PMid:23201407.

18. Madhesh M, Vaiyapuri $M$. Effect of luteolin on lipid peroxidation and antioxidants in acute and chronic periods of isoproterenol induced myocardial infarction in rats. Journal of Acute Medicine. 2012;2(3):70-6. https://doi. org/10.1016/j.jacme.2012.06.001.

19. Ohkawa H, Ohishi N, Yagi K. Assay for lipid peroxides in animal tissues by thio barbituric acid reaction. Anal Biochem. 1979;95(2):351-8. https://doi. org/10.1016/0003-2697(79)90738-3.

20. Yagi K. Lipid peroxides and human disease. Chem Phys Lip. 1978;45:33751. https://doi.org/10.1016/0009-3084(87)90071-5.

21. Jiang ZY, Hunt JV, Wolff SP. Ferrous ion oxidation in the presence of xylenol orange for detectionof lipid hydro peroxides in low density lipoproteins. Anal Biochem. 1992;202(2):384-9. https://doi.org/10.1016/00032697(92)90122-N.

22. Rao KS, Recknagel RO. Early onset of lipo peroxidation in rat liver after CCl4 administration. Exp Mol Pathol. 1968;9(2):271-8. https://doi. org/10.1016/0014-4800(68)90041-5.

23. Kakkar PS, Das B, Viswanathan PN. A modified spectrophotometric assay of super oxide Dismutase. Ind J Biochem Biophy. 1984;21:130-2. PMid:6490072.

24. Sinha KA. Colorimetric assay of catalase. Annul Biochem. 1972;47:387-9. https://doi.org/10.1016/0003-2697(72)90132-7.

25. Rotruck JT, Pope AL, Ganther HE, Swanson AB, Hateman DG, Hoekstra WG. Selenium: Biochemical role as a component of glutathione peroxidase. Science. 1973;179(4073):588-90. https://doi.org/10.1126/ science.179.4073.588.

26. Boyne AF, Ellman GL. A methodology for analysis of tissue sulfahydryl components. Anal. Biochem. 1972;46(2):639-53. https://doi. org/10.1016/0003-2697(72)90335-1.

27. Habig WH, Jakoby WB. Assays for differentiation of glutathione-Stransferases. Meth Enzymol. 1981;77:398-405. https://doi.org/10.1016/ S0076-6879(81)77053-8

28. Omaye ST, Turnbull TD, Sauberlich HE. Selected method for the determination of ascorbic acid in animal cells, tissues and fluid. Enzymol. 1979;62:3-11 https://doi.org/10.1016/0076-6879(79)62181-X.

29. Baker H, Frank O, Angelis B, Feingold S. Plasma tocopherol in man at various times after ingested free acetylated tocopherol. Nutr Rep Int. 1980;21(4):531-6.

30. Duncan BD. Multiple range test for correlated and lesenoscedastic means. Biometri. 1957;13(2):359-64. https://doi.org/10.2307/2527799.

31. Farvin KHS, Anandan R, Kumar SHS, Shiny KS, Sankar TV, Thankappan TK. Effect of squalene on tissue defense system in isoproterenol induced myocardial infarction in rats. Pharmacol Res. 2004;50(3):231-6. https://doi. org/10.1016/j.phrs.2004.03.004 ; PMid:15225664.

32. Arouma, Okezie. Free radicals antioxidants and international nutrition. Asia Pacific Journal of Clinical Nutrition. 1999;8:53-63. https://doi.org/10.1046/ j.1440-6047.1999.00036.x

33. Valko $\mathrm{M}$, et al. Free radicals and antioxidants in normal physiological function and human diseases. Int J Biochem Cell Biol. 2007;39(1):44-84. https://doi. org/10.1016/j.biocel.2006.07.001; PMid:16978905.

34. Yates JC, Dhalla NS. Induction of necrosis and failure in the isolated perfused rat heart with oxidized isoproterenol. J Mol Cell Cardiol. 1975;7(11):807-16. https://doi.org/10.1016/0022-2828(75)90132-7.

35. Bors W, Michael C, Saran M, Lengfelder E. The involvement of oxygen radicals during the auto oxidation of adrenaline. Biochim Biophys Acta. 1995;540(1):162-72. https://doi.org/10.1016/0304-4165(78)90445-2.

36. Dhalla NS, Yates JC, Lee SL, Singh A. Functional and sub cellular changes in the isolated rat heart perfused with oxidized iso proterenol. J Mol Cell Cardiol. 1978;10(1):31-41. https://doi.org/10.1016/0022-2828(78)90004-4.
37. Kumari S, Kumar S, Yogeeta, Gnanapragasam A, Senthilkumar S, Suhasini R, Devaki K. Synergistic Salubrious effect of Ferulic acid and Ascorbic acid on membrane bound Phosphatases and lysosomal hydrolases during experimental myocardial infarction in rats. Life Sciences. 2006;80(3):258-73. https://doi.org/10.1016/j.Ifs.2006.09.012 ; PMid:17045618.

38. Rona G, Chappel Cl, Balaz TR. An infarct like myocardial lesion and other toxic manifestations produced by isoproterenol in the rats. AMA Arch Path. 1959;67(4):443-55. PMid:13636626.

39. Edinger AL, Thompson $\mathrm{CB}$, Death by design: apoptosis, necrosis and autophagy. Curr Opnin Cell Biol. 2004;16(6):663-9. https://doi.org/10.1016/j. ceb.2004.09.011; PMid:15530778.

40. Goldstein P, Kroemer G. Cell Death by Necrosis, towards a molecular definition. Trends Biochem Sci. 2007;32(1):37-41. https://doi.org/10.1016/j. tibs.2006.11.001; PMid:17141506.

41. Hogberg J, Bergstrand A, Jakobsons S V. Lipid peroxidation of rat liver microsome. Eur J Biochem. 1973;37(1):51-9. https://doi. org/10.1111/j.1432-1033.1973.tb02956.x ; PMid:4147089.

42. Mahesh T, Menon VP. Quercetin alleviates oxidative stress in streptozotocin induced diabetic rats. Phytother Res. 2004;18(2):123-7. https://doi. org/10.1002/ptr.1374; PMid:15022163.

43. Formica JV, Regelson W. Review of the biology of quercetin and related bioflavonoid. Food Chem Toxicol. 1995;33(12):1061-80. https://doi. org/10.1016/0278-6915(95)00077-1.

44. Tripoli E, Guardia ML, Giammanco S, Majo DD, Giammanco M. Citrus flavonoids :Molecular structure, biological activity and nutritional properties. Food Chemistry. 2007;104(2):466-9. https://doi.org/10.1016/j. foodchem.2006.11.054.

45. Ferreira JFS, Luthria DL, Sasaki T, Heyerick A. Flavonoids from Artemisia annua as antioxidants and their potential synergism with Artemisinin against malaria and cancer. Molecules. 2010;15(5):3135-70. https://doi.org/10.3390/ molecules15053135; PMid:20657468.

46. Cook NC, Samman S. Flavonoids: Chemistry, metabolism, cardio protective effects and dietary sources. Nutritional Biochemistry. 1996;7(2):66-76. https://doi.org/10.1016/0955-2863(95)00168-9.

47. Miyake Y, Yamamoto K, Tsujihara N, Osawa T. Protective effects of lemon flavonoids on oxidative stress in diabetic rats. Lipids. 1998;33(7):689-95. https://doi.org/10.1007/s11745-998-0258-y.

48. Lobo v, Patil A, PhatakA, Chandra N. Free radicals antioxidants and functional foods: Impact on human health. Pharmacogn Mag. 2010;4(8):118-26. https:// doi.org/10.4103/0973-7847.70902 ; PMid:22228951 PMCid:PMC3249911.

49. Henry WL, Lin KC, Hui YW, Hsien LC, Hongzin L. Antioxidant enzymes activity involvement in luteolin induced human lung squamous carcinoma CH27 cell apoptosis. Eur J Pharmacol. 2006;534(1):12-18.

50. Filho LHG, FNL, Sousa RB, Carvalho ER, Lobo PL. Experimental model of myocardial infarction induced by isoproterenol in rats. Rev Bras Cir Cardiovas. 2011;26(3):469-79. https://doi.org/10.5935/1678-9741.20110024.

51. Murugesan M, Revathi R, Manju V. Cardio protective effect of fenugreek on isoproterenol induced myocardial infarction in rats. Indian J Pharmacol. 2011;43(5):516-9. https://doi.org/10.4103/0253-7613.84957 ; PMid:22021992 PMCid:PMC3195119.

52. Ursini F, Maiorino M, Brigelius FR, et al. The diversity of glutathione peroxidase. Meth Enzymol. 1995;252:38-63. https://doi.org/10.1016/00766879(95)52007-4.

53. Kumar SR, et al. Cardio Protective Effect of Caesalpinia crista Linn on Isoproterenol Induced Myocardial Necrosis in Rats. IJRPS. 2013;3(1):11930.

54. Niki E, Kawakami Y, Yamamoto Y, Kamiya Y. Oxidation of lipids, Synergistic inhibition of phosphatidyl choline liposome in aqueous dispersion by vitamin E and vitamin C. Bull Chem Soc Jpn. 1985;58(7):1971-5. https://doi. org/10.1246/bcsj.58.1971. 
PICTORIAL ABSTRACT

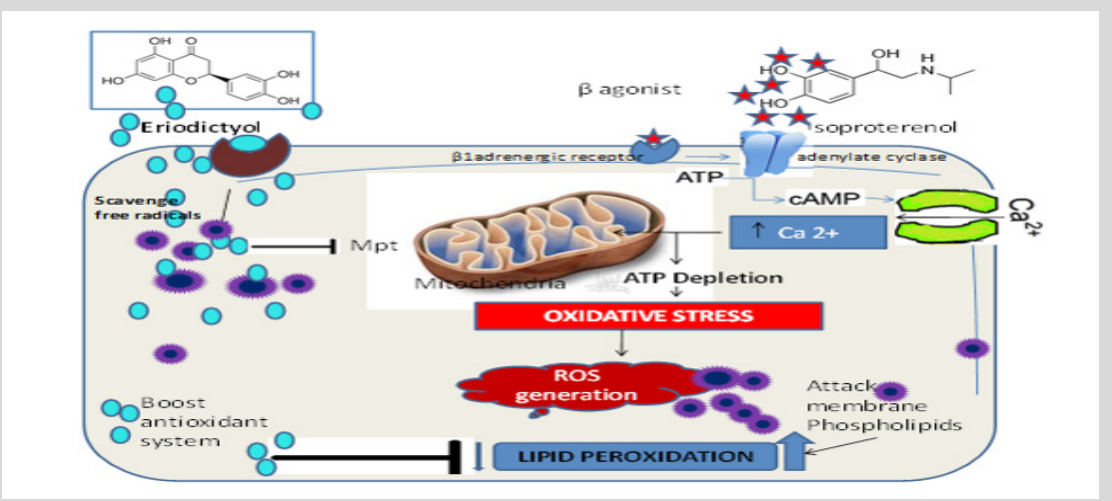

\section{SUMMARY}

- The study showed significant increase in the levels of thiobarbituric acid reactive substances, lipid hydroperoxides and conjugated dienes both in plasma and heart tissue with considerable decrease in the levels of enzymatic and non-enzymatic antioxidants in ISO induced myocardial infracted rats.

- The oral administration of eriodictyol showed significant decrease in lipid peroxidation products and with significant increase in the levels of antioxidants.

- The cardio protective role of eriodictyol was further assessed by histopathological studies.

\section{About Authors}

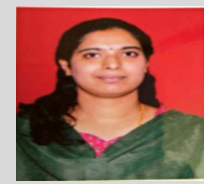

Preethi Hariharan: Ph.D candidate at Department of Biochemistry, Periyar University, Salem, Tamil Nadu, India. Interested in Cancer Biology and Clinical Biochemistry.

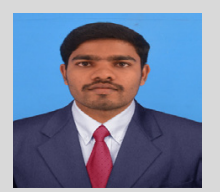

Mariyappan Palani: Ph.D candidate and JRF at Department of Biochemistry, Periyar University, Salem, Tamil Nadu, India. Interested in Cancer Biology and Clinical Biochemistry.

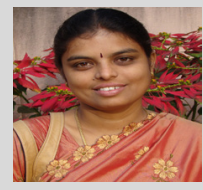

Manju Vaiyapuri: She is Assistant Professor at Periyar University, Salem, Tamil Nadu, India in the Department of Biochemistry. Her educational qualifications - M.Sc., M.Phil., Ph.D. Interested in Cancer Biology and Clinical Biochemistry.

Cite this article: Hariharan P, Palani M, Vaiyapuri M. An Evaluation of Antioxidant Potential of Flavonoid Eriodictyol in Isoproterenol-Induced Myocardial Infarction in Rats. Indian Journal of Pharmaceutical Education and Research. 2017;51(4):603-12. 